\title{
Hepatitis in disseminated bacillus Calmette-Guérin infection
}

\author{
Markus U Göttke MD PhD, Philip Wong MD FRCPC, Channy Muhn MD, Mansour Jabbari MD FRCPC, \\ Suzanne Morin MD FRCPC
}

MU Göttke, P Wong, C Muhn, M Jabbari, S Morin. Hepatitis in disseminated bacillus Calmette-Guérin infection. Can J Gastroenterol 2000;14(4):333-336. Local immunotherapy with an attenuated live strain of Mycobacterium bovis, bacillus CalmetteGuérin (BCG), is an effective and frequently used treatment for in situ transitional cell carcinoma (TCC) of the bladder. Success rates are high, and serious side effects are infrequent but can affect every organ system. A 79-year-old patient with recently diagnosed TCC who was treated with intravesical BCG for a recurrence after initial surgical treatment is reported. After unsuccessful attempts at bladder catheterization with the creation of a false passage for his third treatment, BCG was instilled via a suprapubic catheter the same day and again a week later. Two weeks after the third BCG instillation, the patient presented with profound lethargy and weakness to the point of not being able to get up out of a chair. He was febrile, anorexic, icteric and had hepatosplenomegaly. Disseminated BCG infection was suspected on the basis of history, clinical examination and a liver biopsy that showed noncaseating granulomatous hepatitis. Empirical treatment was started with antituberculous combination therapy. A short course of an oral corticosteroid was given. Clinical improvement was marked and sustained so that the patient could be discharged home for the full six-month course of his treatment. Disseminated BCG infection with granulomatous hepatitis can be severe and life-threatening in cases where a large intravascular inoculum of BCG may have been given inadvertently.

Key Words: Bacillus Calmette-Guérin; Granulomatous hepatitis; Immunotherapy; Infection; Mycobacterium bovis; Syndrome of inappropriate antidiuretic hormone secretion

\section{Hépatite et infection disséminée au bacille de Calmette-Guérin}

RÉSUMÉ : On a souvent recours à l'immunothérapie locale à l'aide d'une souche vivante atténuée de Mycobacterium bovis, bacille de Calmette-Guérin (BCG), pour traiter efficacement les carcinomes in situ de type transitionnel (CTT) de la vessie. Le taux de réussite est élevée et les effets indésirables sérieux sont rares, mais ils peuvent toucher n'importe quel système organique. Voici le cas d'un homme de 79 ans, traité par instillation intravésicale de BCG pour un CTT diagnostiqué depuis peu et réapparu après un premier traitement chirurgical. Après avoir vainement tenté un cathétérisme vésical par la création d'un faux passage pour le troisième traitement, on a instillé la solution de BCG dans la vessie à l'aide d'un cathéter sus-pubien, le même jour et une semaine plus tard. Deux semaines après la troisième instillation de $\mathrm{BCG}$, le patient s'est présenté à l'hôpital, souffrant de profonde léthargie et d'une grande faiblesse, au point de ne pouvoir se lever de sa chaise. Il était fébrile, anorexique, présentait de l'ictère et une hépatosplénomégalie. On a soupçonné la présence d'une infection disséminée au BCG, compte tenu de ses antécédents, de l'examen clinique et de la biopsie du foie qui confirmait la présence d'une hépatite granulomateuse non caséeuse. Un traitement empirique a été amorcé à l'aide d'une association d'antituberculeux, complété par l'administration d'un corticostéroïde par voie orale sur une courte période. Au bout d'un certain temps, l'état clinique du patient s'est grandement amélioré et de façon soutenue, si bien qu'il a pu retourner chez lui pour suivre son traitement complet d'une durée de six mois. Les infections disséminées au BCG avec hépatite granulomateuse peuvent s'avérer graves, voire mortelles, dans les cas où une quantité importante d'inoculum intravasculaire de BCG a été administrée accidentellement.

This article was a winning entry in the Consults in Gastroenterology Case Study Competition, which was initiated and funded with the generous sponsorship of Astra Canada, and it is endorsed by the Canadian Association of Gastroenterology.

Departments of Internal Medicine and Gastroenterology, Montreal General Hospital, McGill University Health Centre, Montreal, Quebec

Correspondence and reprints: Dr Suzanne Morin, Department of Internal Medicine, Montreal General Hospital, 1650 Cedar Avenue, Montreal,

Quebec H3G 1A4. Telephone 514-937-6011 ext 3067, fax 514-937-0803

Accepted for publication July 18, 1999 
Tmmunotherapy of neoplastic disease with bacillus Calmette-Guérin (BCG) has been in use since at least the 1960s for conditions as diverse as malignant melanoma and acute lymphoblastic leukemia $(1,2)$. Intravesical instillation of BCG is the preferred treatment for the early stages of bladder carcinoma (3). Because live bacteria are used, disseminated infection is possible, albeit rare, as long as bladder access is not traumatic. In cases of BCG instillation after traumatic catheterization, granulomatous hepatitis following hematogenous dissemination can be a life-threatening complication of treatment. A case of BCG hepatitis with syndrome of inappropriate antidiuretic hormone secretion (SIADH) is described, and treatment options in this and previously published cases are discussed.

\section{CASE PRESENTATION}

A 79-year-old patient was transferred to the authors' institution for workup because of a three-week history of malaise, fever with infrequent chills, progressive fatigue with somnolence and anorexia. Seven months before admission, the patient had been diagnosed incidentally with superficial transitional cell carcinoma (TCC) of the bladder (stage T1, invasion into the lamina propria) during a routine examination for benign prostatic hypertrophy. He had been previously healthy, and his only hospital admissions were for a remote cholecystectomy and for an operation of esophageal diverticula in 1990. Initial treatment of the TCC included tumour resection with concomitant retropubic prostatectomy. Cystoscopic follow-up showed local recurrence of disease in October 1998. Local immunotherapy with weekly intravesicular instillations of BCG was subsequently started by the treating urologist. The first two instillations were accomplished through a Foley catheter on December 7 and 14 without complication. For the third treatment a week later, several attempts to insert the Foley catheter with the creation of a false passage into the bladder were unsuccessful. It was then decided to place a suprapubic catheter and instill BCG via this route that same day. That evening, the patient had chills, and over the following week he had a constant fever over $38^{\circ} \mathrm{C}$ and started to develop anorexia and fatigue. On December 28, a fourth instillation of BCG was administered, again through the suprapubic catheter. On January 4, the patient was admitted with fever, anorexia, icterus and profound fatigue. The patient was found to be leukopenic (leukocytes $1.8 \times 10^{8} / \mathrm{L}$ ) and anemic (hemoglobin $100 \mathrm{~g} / \mathrm{L}$ ); aspartate (AST) and alanine (ALT) aminotransferase levels were twice their normal values, gamma-glutamyltranspeptidase $(\gamma-G T)$ level was 1.5 times the normal value and alkaline phosphatase (AP) level was twice the normal value. The patient was hypoalbuminemic, with a serum albumin level of $26 \mathrm{~g} / \mathrm{L}$. Results of a chest radiograph and an electrocardiogram were normal. The patient was started on cefotaxime intravenously, which he received for six days without clinical improvement. Treatment with rifampin was suggested by a consulting physician, but it is unclear whether a dose was given before the patient was transferred to the authors' institution on January 11.
On admission to the Montreal General Hospital, Montreal, Quebec, the patient looked pale and unwell. He was somnolent and so weak that he could not rise from a sitting position. Cachexia with a body mass index of 17 was noted. His blood pressure was $140 / 70 \mathrm{mmHg}$, and heart rate was 92 beats/min. Examination of the pulmonary and the cardiovascular systems yielded normal findings. Scleral icterus and hepatosplenomegaly were noted. The liver was tender and felt at $8 \mathrm{~cm}$ below the right costal margin, with a liverspan of approximately $20 \mathrm{~cm}$ in the right midclavicular line. The spleen was notably enlarged and palpable $4 \mathrm{~cm}$ below the left costal margin. Bowel sounds were found to be normal, and the stool was negative for occult blood. A suprapubic catheter was in place. Mild below-knee edema was noted. There were no meningeal signs. An abdominal ultrasound showed a small right pleural effusion and splenomegaly of $14 \mathrm{~cm}$, intrahepatic and extrahepatic bile ducts were not dilated, and no gallstones were seen. Laboratory investigations revealed mild leukopenia (leukocytes $2.8 \times 10^{8} / \mathrm{L}$; neutrophils $2.0 \times 10^{8} / \mathrm{L}$ ) and anemia, with a hemoglobin level of $109 \mathrm{~g} / \mathrm{L}$, a mean corpuscular volume of $78.2 \mathrm{fL}$ and a platelet count of $197 \times 10^{9} /$ L. The partial thromboplastin time was slightly elevated at $36.7 \mathrm{~s}$, with a normal prothrombin time. Total bilirubin was elevated to $36 \mu \mathrm{mol} / \mathrm{L}$, with a direct bilirubin level of $32 \mu \mathrm{mol} / \mathrm{L}$, AP level was $412 \mathrm{U} / \mathrm{L}, \gamma$-GT $278 \mathrm{U} / \mathrm{L}$, AST $108 \mathrm{U} / \mathrm{L}$, ALT $55 \mathrm{U} / \mathrm{L}$, albumin $24 \mathrm{~g} / \mathrm{L}$ and total protein $54 \mathrm{~g} / \mathrm{L}$. Sodium was $127 \mathrm{mmol} / \mathrm{L}$, potassium $3.8 \mathrm{mmol} / \mathrm{L}$, chloride $94 \mathrm{mmol} / \mathrm{L}$, bicarbonate $28 \mathrm{mmol} / \mathrm{L}$, blood urea nitrogen $5.8 \mathrm{mmol} / \mathrm{L}$ and creatinine $76 \mu \mathrm{mol} / \mathrm{L}$. Results of a urine analysis were normal.

Disseminated BCG infection was diagnosed based on the clinical findings and the history of BCG instillation after traumatic catheterization of the bladder. Antimycobacterial treatment was initiated on admission with ofloxacin, amikacin, ethambutol and prednisone.

Liver biopsy on the second day of admission showed multiple granulomata scattered at random throughout the parenchyma (Figure 1), not associated with any specific microanatomical liver structure. The granulomata were noncaseating and contained Langerhans' giant cells (Figure 2). Ziehl-Neelsen staining was negative for acid-fast bacilli (Figure 3). Grocott and periodic acid-Schiff staining were negative for other microorganisms such as Histoplasma capsulatum, fungi or Pneumocystis carinii. Foreign body inclusions were not seen, and only an occasional eosinophil was detected around the granulomata.

Improvement of the patient's clinical condition was initially slow, and during the first week was most notable for an increase in alertness despite a worsening hyponatremia compatible with SIADH (sodium $121 \mathrm{mmol} / \mathrm{L}$, urinesodium $81 \mathrm{mmol} / \mathrm{L}$, urine osmolality $429 \mathrm{mOsm} / \mathrm{L}$ ). This was managed successfully with fluid restriction. A right lower lobe infiltrate noted on chest radiography on the second day did not have a miliary appearance on high resolution computed tomography and was thought to be secondary to an aspiration pneumonia. No additional antibiotics were administered, and the infiltrate resolved rapidly. The pro- 


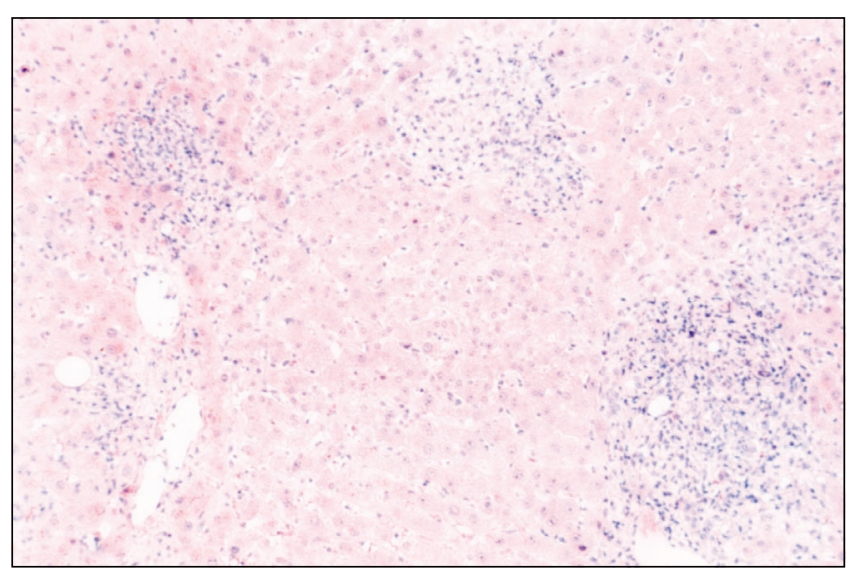

Figure 1) Liver biopsy taken on the day of commencement of antituberculous therapy. Numerous granulomata can be seen that are not associated with any particular microanatomical feature of the liver (hematoxylin and eosin stain, original magnification $\times 100$ )

found weakness of the patient coupled with a continuing anorexia made feeding via a nasogastric tube necessary. In the first five days, liver enzyme levels peaked (AP $615 \mathrm{U} / \mathrm{L}$, $\gamma$-GT $502 \mathrm{U} / \mathrm{L}$, AST $193 \mathrm{U} / \mathrm{L}$ and ALT $104 \mathrm{U} / \mathrm{L}$ ) and then fell steadily. At this point, amikacin was replaced with isoniazid (INH) as a more effective drug, supplemented with pyridoxine. Prednisone was tapered rapidly. From then on, a steady clinical improvement was observed. Nasogastric feeding was discontinued, and the patient was able to get up with help for the first time on the ninth day of admission. He was discharged home 23 days after admission, still requiring intensive home care by his local health station.

On his first follow-up visit, the patient had further improved clinically. His liver was still enlarged and was palpable at $4 \mathrm{~cm}$ below the costal margin. The spleen was not felt. Bilirubin and ALT levels were within the normal range; AP and $\gamma$-GT levels were still elevated at $168 \mathrm{U} / \mathrm{L}$ and $115 \mathrm{U} / \mathrm{L}$, respectively. Results of a Mendel-Mantoux test done at this point were negative. The patient is currently completing a six-month course of antimycobacterial therapy.

\section{DISCUSSION}

BCG is a viable strain of the virulent Mycobacterium bovis attenuated through laboratory passage. It was developed during the closing years of the 19th century in the race to find a vaccine against tuberculosis, and in this context it was successfully employed for the first time in the 1920s (2). Around that time, it was already observed that mycobacterial infection might have a mitigating effect on malignant disease (2). Since the 1960s, BCG has been used as an immunotherapeutic agent in acute lymphoblastic leukemia, in malignant melanoma and particularly in TCC of the bladder $(1,4,5)$. Today, local BCG immunotherapy for early stages of TCC is a well established treatment option, with success rates ranging from $64 \%$ to $94 \%$ - higher than for any chemotherapeutic agent (2).

Granulomatous hepatitis is a rare complication of BCG

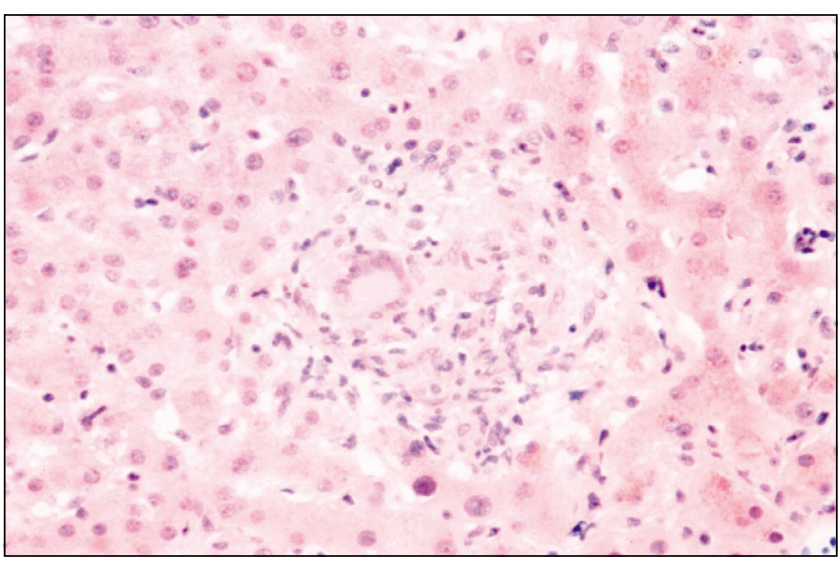

Figure 2) Noncaseating granuloma with Langerhans' giant cells; no eosinophils are seen (hematoxylin and eosin stain, original magnification $\times 400)$

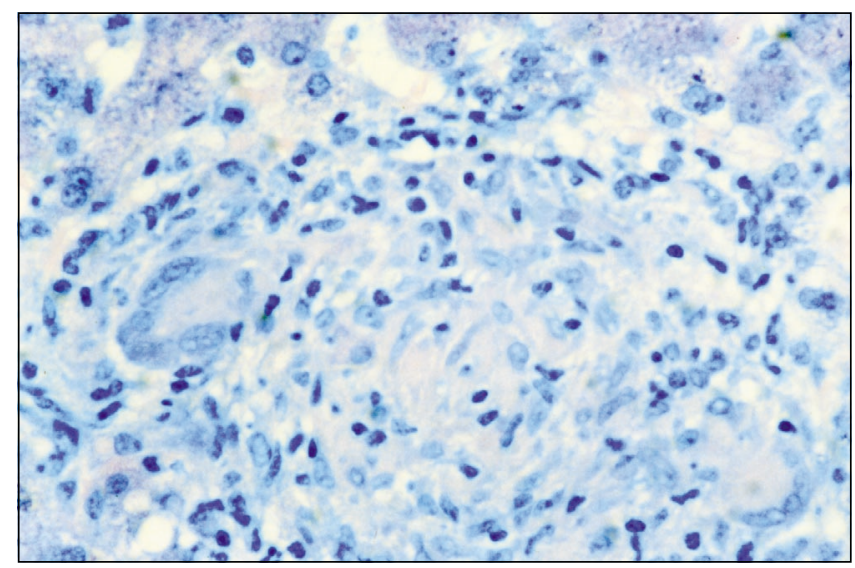

Figure 3) Noncaseating granuloma with Langerhans' giant cells; no acid-fast bacilli are seen (Ziehl-Neelsen stain, original magnification $\times 400$ )

immunotherapy. Despite the frequent use of BCG, only about two dozen cases of hepatitis have been described since its introduction 25 years ago (3,6-16). Side effects such as dysuria, frequency of urination, hematuria and a passing fever seem to be the hallmark of a successful BCG treatment. About 100 million live organisms suspended in saline are instilled in each of six sessions, usually a week apart (17). A vigorous immune response against the bacteria is mounted, leading to a severe granulomatous cystitis. The mechanisms underlying the eradication of cancerous cells are poorly understood but thought to depend on the induction of local inflammation, leading to the release of numerous immunologically active substances and a nonspecific immune response $(3,16)$. Thus, relatively minor local complications such as prostatitis are not uncommon (11). It is easily imaginable that low level subclinical dissemination of BCG to various organs is more common than is recognized; however, severe systemic complications such as clinically apparent hepatitis, pneumonitis or a septic presentation tend to occur after difficult and traumatic catheterizations of the bladder $(16,18,19)$, situations in which large inoculates of BCG gain 
easy access to the bloodstream. Instillation of BCG via a suprapubic catheter after failed catheterization of the urethra, as in our patient, has not been mentioned to date.

Clinically apparent granulomatous hepatitis can be the leading finding in disseminated BCG infection or can be associated with granulomatous infiltration of other organs such as the lungs (11). The disease usually starts within hours of a traumatic catheterization, with chills and a general malaise, but can be delayed for over a year after BCG therapy (8). As in our patient, BCG hepatitis tends to present with cholestatic rather than hepatocellular injury, with bilirubinemia and significantly elevated AP and $\gamma$-GT levels. Patients are febrile and appear sick on examination. More often than not, the liver is enlarged and painful upon palpation. Abdominal ultrasound may pick up mild hepatosplenomegaly but is otherwise noncontributory. SIADH in conjunction with disseminated BCG infection has not been described previously. In our patient, it may well have contributed to the impressive apathy. BCG hepatitis is generally diagnosed on the basis of the history and the clinical examination as well as of the alterations seen in liver function tests.

Proof of infection is notoriously difficult. Only $10 \%$ of acid-fast stains are positive in cases of tuberculosis of the liver. The same seems to hold true for BCG, where mycobacteria were seen on histological examination in only two cases of biopsy-proven granulomatous hepatitis - once by ZiehlNeelsen staining and once by auramine-rhodamine fluorescent staining $(13,16)$. Blood and biopsy cultures have a similar or even lower yield, and even molecular techniques are not reliable (19). This diagnostic difficulty together with the observation of eosinophils in some biopsies has led to a discussion of the role of hypersensitivity reactions after intravesical BCG treatment $(12,14)$. As in the present case,

\section{REFERENCES}

1. Mathé G, Amiel J, Schwartzenberg L, et al. Active immunotherapy for acute lymphoblastic leukemia. Lancet 1969;i:697-9.

2. Morales A, Nickel JC. Immunotherapy for superficial bladder cancer. A developmental and clinical overview. Urol Clin North Am 1992;19:549-56.

3. Barza MJ, Blum JH, Graeme-Cook FM. Case records of the Massachusetts General Hospital. Weekly clinicopathological exercises. Case 29-1998. A 57-year-old man with fever and jaundice after intravesical instillation of bacille Calmette-Guérin for bladder cancer. N Engl J Med 1998;339:831-7.

4. Zbar B, Bernstein ID, Bartlett GL, Hanna MJ Jr, Rapp HJ. Immunotherapy of cancer: regression of intradermal tumors and presentation of growth of lymph node metastases after intralesional injection of living Mycobacterium bovis. J Natl Cancer Inst 1972;49:119-30.

5. Morales A, Eidinger D, Bruce AW. Intracavitary bacillus Calmette-Guérin in the treatment of superficial bladder tumors. J Urol 1976;116:180.

6. Rosenberg SA, Seipp C, Sears HF. Clinical and immunologic studies of disseminated BCG infection. Cancer 1978:41:1771-80.

7. Flippin T, Mukherji B, Dayal Y. Granulomatous hepatitis as a late complication of BCG immunotherapy. Cancer 1980;46:1759-62.

8. Marans HY, Bekirov HM. Granulomatous hepatitis following intravesical bacillus Calmette-Guérin therapy for bladder carcinoma. J Urol 1987;137:111-2.

9. Thompson D, Cumming J. Granulomatous hepatitis following intravesical BCG therapy. Br J Urol 1990;66:432-3. most authors tend to include steroids in the regimen, but do not discontinue antituberculous drugs in the case of negative stains and cultures $(3,16)$. Interestingly, the MendelMantoux tests done in our patient four weeks after diagnosis and six weeks after the first traumatic instillation of BCG were nonreactive, and only very few eosinophils were seen on examination of the liver biopsy. This result does not support a hypersensitivity reaction as the cause for the granulomatous infiltrates.

Antituberculous treatment is complicated by the fact that, particularly INH, the most potent drug available, but also rifampin, induce hepatitis on a frequent basis. Departing from the 1992 recommendations, which included the use of both drugs (11), we chose an initial regimen that replaced INH and rifampin with ofloxacin (400 mg orally bid) and amikacin (500 mg intravenously every $12 \mathrm{~h}$ ) given together with ethambutol $(1200 \mathrm{mg} /$ day orally) and prednisone (60 mg/day orally). Once a sustained improvement of liver enzyme levels was observed, amikacin was replaced with INH (300 mg/day orally) and prednisone was tapered over two weeks.

The case reported here highlights granulomatous hepatitis as a possible complication from dissemination of BCG in the course of immunotherapy of bladder carcinoma. The potential severity of BCG infection is illustrated in a case where a large inoculum may have gained access to the bloodstream through a suprapubic catheter after failed traumatic urethral catheterization.

ACKNOWLEDGEMENTS: The authors thank Dr S Tanguay, Dr D Portnoy and Dr D Eidelman for discussion of treatment strategies, and Dr JO Lough for help with the histological stains. The generous support from Astra Canada indicates their commitment to very worthwhile educational initiatives in gastroenterology

10. Graziano DA, Jacobs D, Lozano RG, Buck RL. A case of granulomatous hepatitis after intravesical bacillus Calmette Guérin administration. J Urol 1991;146:1118-9.

11. Lamm DL, van der Meijden PM, Morales A, et al. Incidence and treatment of complications of bacillus Calmette-Guérin intravesical therapy in superficial bladder cancer. J Urol 1992;147:596-600.

12. Molina JM, Rabian C, D’Agay MF, Modai J. Hypersensitivity systemic reaction following intravesical bacillus Calmette Guérin: successful treatment with steroids. J Urol 1992;147:695-7.

13. Proctor DD, Chopra S, Rubenstein SC, Jokela JA, Uhl L. Mycobacteremia and granulomatous hepatitis following initial intravesical bacillus Calmette-Guérin instillation for bladder carcinoma. Am J Gastroenterol 1993;88:1112-5.

14. Lyons D, Miller I, Jeffers A. Systemic hypersensitivity reaction to intravesical BCG. Scott Med J 1994;39:49-50.

15. Arzt MR, Forouhar F. Granulomatous hepatitis as a complication of intravesical bacillus Calmette Guérin therapy for bladder carcinoma. Ann Clin Lab Sci 1995;25:409-13.

16. Leebeek FWG, Ouwendijk RJT, Kolk AHJ, et al. Granulomatous hepatitis caused by bacillus Calmette-Guérin (BCG) infection after BCG bladder instillation. Gut 1996;38:616-8.

17. Sosnowski JT. Complications of bacillus Calmette-Guérin (BCG) immunotherapy in superficial bladder cancer. Compr Ther 1994;20:695-701.

18. Brosman SA. Bacillus Calmette-Guérin immunotherapy. Techniques and results. Urol Clin North Am 1992;19:557-64.

19. Lamm DL. Complications of bacillus Calmette-Guérin immunotherapy. Urol Clin North Am 1992;19:565-72. 


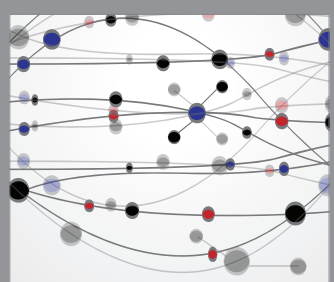

The Scientific World Journal
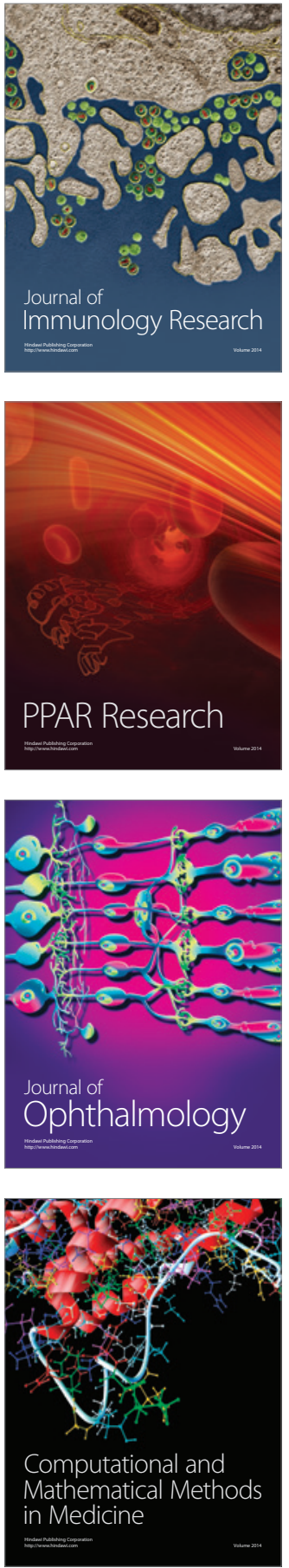

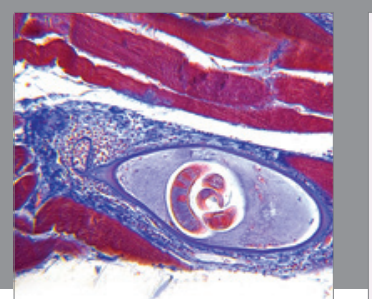

Gastroenterology Research and Practice

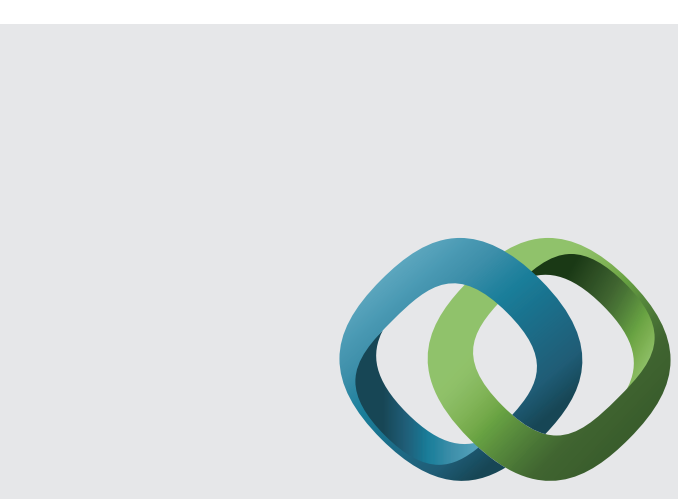

\section{Hindawi}

Submit your manuscripts at

http://www.hindawi.com
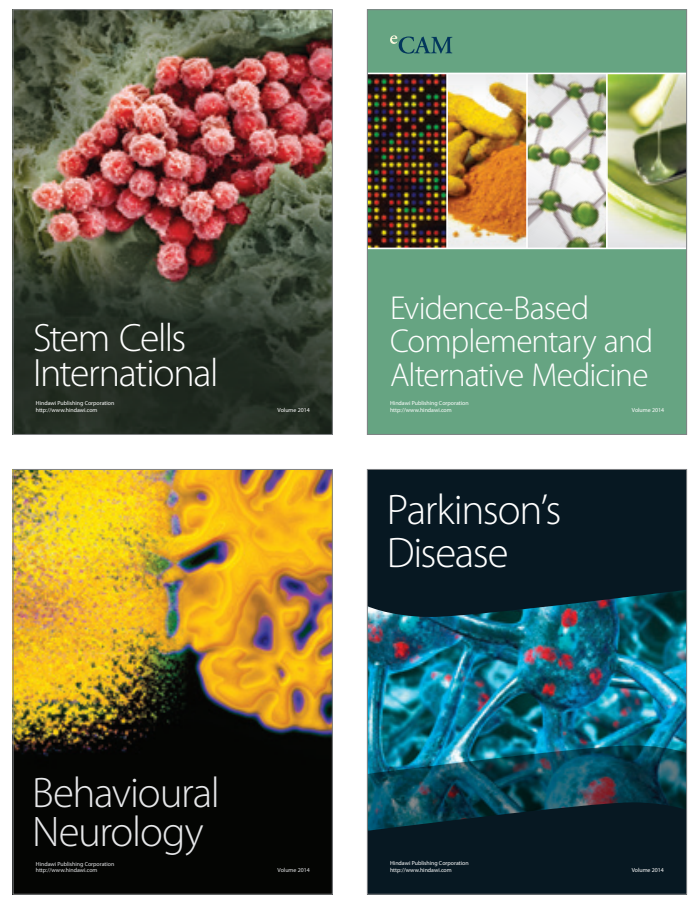
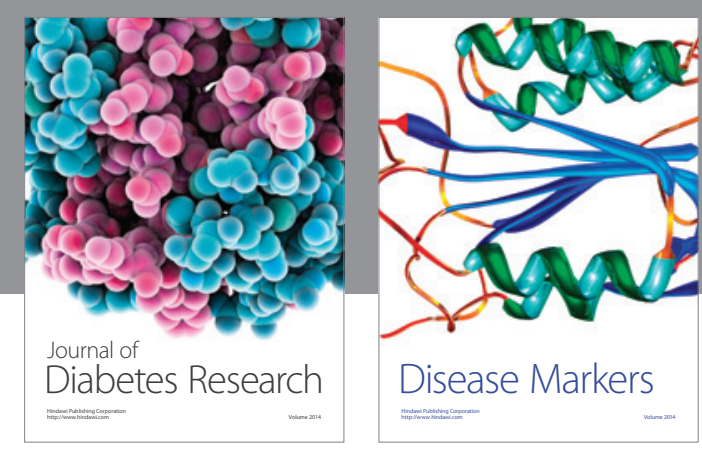

Disease Markers
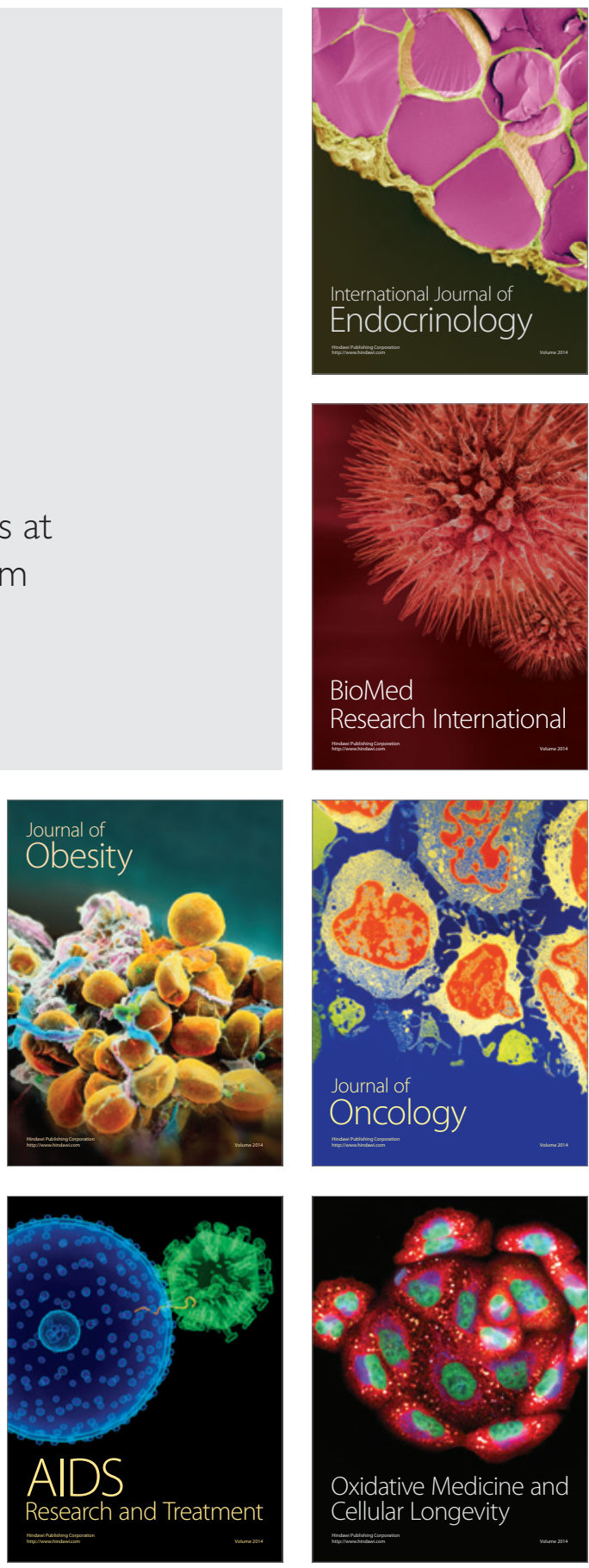